\title{
Bibliometric Study of Publications on Impact of Covid-19 and Sleep Disorders
}

\author{
Sandeep Grover ${ }^{1, *}$, BM Gupta ${ }^{2}$, GM Mamdapur ${ }^{3}$, M Surulinathi ${ }^{4}$ \\ 'Post Graduate Institute of Medical Education and Research, Chandigarh, INDIA. \\ ${ }^{2}$ Formerly with CSIR-NISTADS, New Delhi, INDIA. \\ ${ }^{3}$ Synthite Industries (P) Ltd, Kolenchery, Kerala, INDIA. \\ ${ }^{4}$ Bharathidasan University, Department of LIS, Tiruchirappalli, Tamil Nadu, INDIA.
}

\begin{abstract}
The paper examines global research output (1656 records) on "Impact of Covid-19 on Sleep Disorders", based on publications indexed in Scopus database. The global publications on this theme averaged 15.05 citations per paper. About $19.02 \%$ share of its total publications on this theme received external funding support and averaged 34.59 citations per paper. Ninety five countries unevenly partcipitated in global research output on "Impact of Covid-19 on Sleeping Disorders", of which the top 10 most productive countries accounted for $87.62 \%$ and more than $100 \%$ share in global publications and citations. The USA, China and Italy led in global publications ranking and productivity as against China (2.52), U.K.(2.26) and Italy (1.67) leading in terms of relative citation index. The 527 organizations and 773 authors participated in global research on this theme, with top 15 most productive organizations and authors contributing to $21.62 \%$ and $6.28 \%$ global publications share and $63.70 \%$ and $56.20 \%$ global citations share. Huazhong University of Science \& Technology, China, and Tongji Medical College, China and Harvard Medical School, USA were the most productive global organizations (with 40, 38 and 33 papers) and Capital Medical University, China (153.85 and 10.22), Wuhan University,
\end{abstract}

China (109.33 and 7.26) and Renmin Hospital of Wuhan University, China (108.10 and 7.18) were the leading most impactful organizations in terms of citation per paper and relative citation index. Z. Liu, S. Grover and G. Wang were the most productive authors (with 9, 8 and, 8). L.Kang (395.17 and 26.26), Y. Wang (395.17 and 26.26) and, S. Ma (322.0 and 21.4) were the most impactful authors. International Journal of Environment Research \& Public Health, Sleep Medicine and Frontiers in Psychiatry were the most productive journals (with 73, 69 and 49 papers). Brain, Behavior \& Immunity (86.04)., Asian Journal of Psychiatry (46.78), Psychiatry Research (41.15) were the most impactful journals.

Key words: Covid-19, Impact, Sleep disorders, Global, Publications, Scientometrics, Bibliometrics

\section{Correspondence}

\section{Prof. Sandeep Grover,}

Post Graduate Institute of Medical Education and Research, Chandigarh, INDIA.

Email id: drsandeepg2002@yahoo.com

DOI: $10.5530 /$ jyp.2021.13s.74

\section{INTRODUCTION}

Sleep is one of the most important biological function, which plays an important role in restoration of body. Sleep deprivation affects every organ of the body and chronic sleep deprivation can lead to emotional instability, poor cognitive functioning, poor pain tolerance, metabolic disturbances, and immunodeficiency. ${ }^{1}$ Sleep is also affected by the stress response and stress has adverse impact on the sleep parameters. ${ }^{2}$ Covid-19 pandemic has emerged as a significant stressful situation for all the human being and it has led to significant psychological distress. Various psychological consequences of Covid-19 pandemic include anxiety, depression, stress and sleep disorders. ${ }^{3}$ Many studies have reviewed the impact of Covid-19 on sleep. ${ }^{4,5}$ Although some of the studies have used bibliometrics methods to assess the literature on sleep disorders, none of the studies have evaluated the literature on "Sleep and Covid-19", using the bibliometric analysis. Bibliometrics is widely used in a variety of fields to measure and evaluate scientific research quantitatively and qualitatively. ${ }^{6}$

In terms of previous bibliometric studies on sleep, there are only a handful of studies. One of the earliest studies evaluated the literature on sleep published from 1974-2004 and the authors reported that the sleep literature quadrupled over 30 years (2384 publications in 1974 and 9721 in 2004), with overall scientific productivity being doubled during the same time frame. The set of the seven most productive countries in sleep research and the geographical region distribution remained stable over the three decades. On the other hand several indicators appeared in the sleep research literature during the 1990s, i.e., the increasing productivity of sleep researchers, researchers from larger number of countries publishing papers on sleep; the continuous creation of sleep-focused journals; the scattering of sleep publication among increasingly more scientific journals; the turnover among the leading journals; and the emergence of new countries such as China, Turkey, and the European Union in the sleep literature. ${ }^{7}$ One of the recent studies evaluated the publications on insomnia. This study included 16,478 articles on insomnia listed in the SCI-Expanded journal lists from 1991 to 2018. The publications were assessed regarding their document types, languages, and journals, using three indicators to determine the citation received by the publications. ${ }^{8}$ Another paper evaluated the top 100 cited articles dedicated to sleep medicine published in various journals that made key contributions to the field. ${ }^{9}$ The authors examined the characteristics of the articles, such as the number of citations, ranking, authorship, article title, year of publication, publishing journal, publication type, and topic categories.

As none of the bibliometric studies have focused on "Impact of Covid-19 on Sleep Disorders", this study aimed to understand the bibliometric characterstics of global literature and to study the research trends. Additional aim include evaluation of source of publications in terms of countries, organizations, authors and journals, besides identifying the scatter of literature across broad subjects and keywords for understanding the research trends.

This is an open access article distributed under the terms of the Creative Commons Attribution-NonCommercial-ShareAlike 4.0 License, which allows others to remix, tweak, and build upon the work non-commercially, as long as the author is credited and the new creations are licensed under the identical terms. 


\section{MATERIALS AND METHODS}

For this study, the publications were identified, retrievied and downloaded from the the Scopus database (http://www.scopus.com) on 14 May 2021 using a comprehensive search strategy. Two types keywords related to "Covid-19" and "Sleeping Disorders" were used in "Keyword"” and in "Article Title" tags (joined by Bolean operator "or") of the Scopus database, yielding 1656 publications. The search strategy was further refined first by country and secondly by subject, collaborating country, organization, author and journal. Citations to publications were counted from date of their publication till 14 May 2021.

\section{RESULTS}

\section{Publication Growth}

The search on "Impact of Covid-19 on Sleep Disorders: yielded 1656 publications with 544 published in the year 2020 and 1112 published during 2021. These publications were cited 24, 928 times, with average citation per paper (CPP) being 15.05 . Only one-fifth $(n=315 ; 19.02 \%)$ of the papers were supported by extramural funding and the CPP for these papers was 34.59. The major agencies which provided funding support to publications on sleep disorders during the Covid-19 pandemic were National Natural Science Foundation of China (57 papers), U.S. Department of Health and Human Services (54 papers), National Institute of Health, USA (53 papers), Ministry of Science and Technology of People's Republic of China (29 papers), National Key Research and Development Program of China (25 papers), and the European Commision (20 papers), etc.

The research articles constituted the largest share (63.04\%) of papers, followed by letters (16.3\%), reviews (10.57\%), editorial $(5.19 \%)$, notes (3.68\%), and other publications (such as short surveys, conference papers, retracted, book chapter and erratum), each of which accounted for $<1 \%$ of the total publications.

\section{Top Ten Most Productive Countries}

The research on 'Impact of Covid-19 on Sleep Disorders" emerged from 95 countries, with top 10 countries contributing to 61 to 386 papers and together accounted for $87.62 \%$ share of global publications outout and more than $100 \%$ share of global citations (Table 1). The maximum number of publications emerged USA (23.3\%) and China (15.46\%). The relative citation index (RCI) for publications from China (2.52), United
Kingdom ( 2.26) and Italy (1.67) was above the group average RCI of of 1.63. The share of international collaborative papers for the top 10 countries varied from $20.44 \%$ to $63.93 \%$, with an average of $37.97 \%$ (Table 1 ).

\section{Collaboration among Top 10 Countries}

Researchers from all the top 10 countries had one-to one collaborative linkages among themselves and these linkages varied from 37 to 154 . The largest number of collaborative linkages were between researcher from USA and China, followed by USA and U.K., USA and Canada, USA and Italy, U.K. Spain, and Italy and Spain (Table 2 and Figure 1).

\section{Subject-Wise Distribution of Global Research Output}

Amongseven broadsubjects(asidentifiedinScopusdatabase) contributing to global literature on "Impact of Covid-19 on Sleep Disorders", Medicine accounted for the largest publication share (83.94\%), followed by Neuroscience (19.38\%), Psychology (10.21\%), Biochemistry, Genetics and Molecular Biology, Environment Science, Pharmacology, Toxicology and Pharmaceutics and Immunology and Microbiology. Publications listed under the subject heading of Immunology and Microbiology registered the largest $\mathrm{CPP}$ (50.75) and least CPP was for the publications covered under the subject heading of Pharmacology, Toxicology and Pharmaceutics (3.61) (Table 3).

\section{Important Keywords}

The literature search yielded 34 most significant keywords which appeared in the literature on "Impact of Covid-19 on Sleep Disoders" (Table 4).

Figure 3 represents the word cloud created using R-Studio's Biblioshiny applications based on keyword frequency in the literature

\section{Top 15 Most Productive Organizations}

Overall researchers from 527 organizations participated in the research on "Impact of Covid-19 and Sleep Disorders", with authors from 365 organizations publishing 1-5 papers each, researchers from 120 organizations publishing 6-10 papers each, researchers from 35 organizations publishing 11-20 papers each and researchers from 7 organizations publishing 21-40 papers each. The productivity of top 15 most productive organizations varied from 16 to 40 publications per organization; and together these organizations contributed to $21.62 \%$ of the total publications, but had $63.7 \%$ of the total citations on the topic

Table 1: Profile of Top 10 Countries on "Impact of Covid-19 on Sleep Disorders"

\begin{tabular}{|c|c|c|c|c|c|c|c|c|c|}
\hline S.No & Name of the Country & TP & $\mathrm{TC}$ & CPP & $\%$ TP & $\mathrm{HI}$ & ICP & $\% I C P$ & $\mathrm{RCl}$ \\
\hline 1 & USA & 386 & 8396 & 21.75 & 23.31 & 36 & 129 & 33.42 & 1.45 \\
\hline 2 & China & 256 & 9702 & 37.90 & 15.46 & 35 & 77 & 30.08 & 2.52 \\
\hline 3 & Italy & 159 & 3998 & 25.14 & 9.60 & 30 & 52 & 32.70 & 1.67 \\
\hline 4 & U.K. & 145 & 4941 & 34.08 & 8.76 & 23 & 81 & 55.86 & 2.26 \\
\hline 5 & India & 137 & 2379 & 17.36 & 8.27 & 17 & 28 & 20.44 & 1.15 \\
\hline 6 & Canada & 83 & 1495 & 18.01 & 5.01 & 17 & 48 & 57.83 & 1.20 \\
\hline 7 & Spain & 76 & 1214 & 15.97 & 4.59 & 14 & 36 & 47.37 & 1.06 \\
\hline 8 & France & 75 & 1579 & 21.05 & 4.53 & 19 & 32 & 42.67 & 1.40 \\
\hline 9 & Brazil & 73 & 753 & 10.32 & 4.41 & 10 & 29 & 39.73 & 0.69 \\
\hline \multirow[t]{3}{*}{10} & Germany & 61 & 1105 & 18.11 & 3.68 & 12 & 39 & 63.93 & 1.20 \\
\hline & Total & 1451 & 35562 & 24.51 & 87.62 & 21.3 & 551 & 37.97 & 1.63 \\
\hline & World & 1656 & 24928 & 15.05 & 100.0 & & & & \\
\hline
\end{tabular}

TP=Total Papers; TC=Total Citations; CPP=Citations Per Paper; ICP=International Collaborative Papers; HI=H-Index; RCI=Relative Citation Index 
Table 2: Size of Collaborative Linkages among Top 10 Countries in "Impact of Covid-19 on Sleep Disorders"

\begin{tabular}{|c|c|c|c|}
\hline S.No & $\begin{array}{l}\text { Name } \\
\text { of the } \\
\text { Country }\end{array}$ & $\begin{array}{l}\text { Collaborative linkages with other } \\
\text { countries }\end{array}$ & $\mathrm{TCL}(\mathrm{NOC})$ \\
\hline 1 & USA & $\begin{array}{l}2(27), 3(20), 4(27), 5(12), 6(25) .7(9), 8(10), \\
9(12), 10(12)\end{array}$ & $154(9)$ \\
\hline 2 & China & $\begin{array}{l}\text { 1(27),3(3), 4(10), 5(1), 6(13), 7(1), 8(1), } \\
9(1), 10(5)\end{array}$ & $62(9)$ \\
\hline 3 & Italy & $\begin{array}{l}\text { 1(20), 2(3), 4(16), 5(2), 6(6), 7(14), 8(11), } \\
9(3), 10(14)\end{array}$ & $86(9)$ \\
\hline 4 & U.K. & $\begin{array}{l}1(27), 2(10), 3(16), 5(6), 6(10), 7(15), 8(11), \\
9(8), 10(13)\end{array}$ & $116(9)$ \\
\hline 5 & India & $\begin{array}{l}1(12), 2(1), 3(2), 4(6), 6(6), 7(1), 8(3), 9(4), \\
10(2)\end{array}$ & $37(9)$ \\
\hline 6 & Canada & $\begin{array}{l}1(25), 2(13), 3(6), 4(10), 5(6), 7(6), 8(9) \\
9(6), 10(6)\end{array}$ & $87(9)$ \\
\hline 7 & Spain & $\begin{array}{l}\text { 1(9), 2(1), 3(14), 4(15), 5(1), 6(6), 8(7), } \\
9(7), 10(7)\end{array}$ & $67(9)$ \\
\hline 8 & France & $\begin{array}{l}\text { 1(10), 2(1), 3(11), 4(11), 5(3), 6(9), 7(7), } \\
9(4), 10(9)\end{array}$ & $65(9)$ \\
\hline 9 & Brazil & $\begin{array}{l}\text { 1(12), 2(1), 3(3), 4(8), 5(4), 6(6), 7(7), 8(4), } \\
10(5)\end{array}$ & $46(9)$ \\
\hline 10 & Germany & $\begin{array}{l}1(12), 2(5), 3(14), 4(13), 5(2), 6(6), 7(7), \\
8(9), 9(5)\end{array}$ & $73(9)$ \\
\hline
\end{tabular}

${ }^{*} \mathrm{TCL}=$ Total collaborative linkages; $\mathrm{NOC}=$ Number of countries

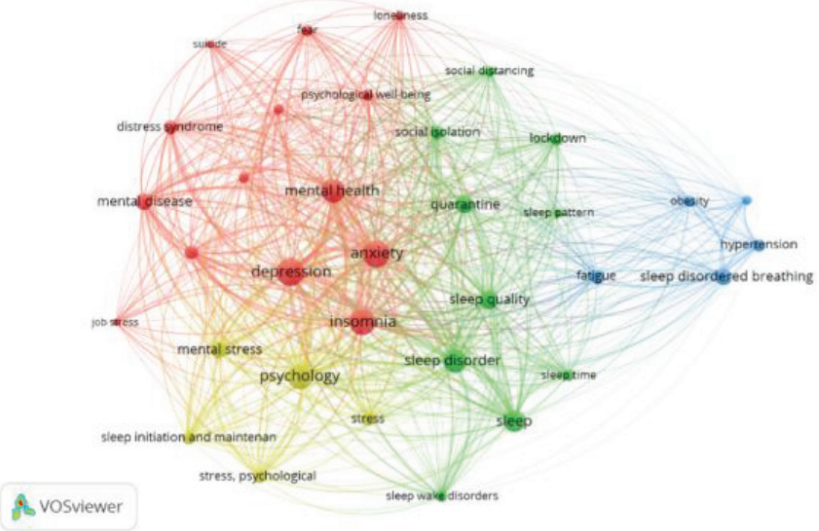

Figure 1: Networks Map of Top-10 highly collaborated countries.

Figure 1 using the VOS viewer visualization tool presents the collaboration network of top-10 countries. Predominantly countries are devided in to two clusters based on closely related nodes or collaboration. The size of the dot represents the number of publications; thickness of the link and distance between the countries represents degree of research collaborations. The USA, China, India and Canada are placed in Cluster- 1 in green color and remainings six countries are placed in second cluster in red color. Map shows all the 10 countries had collaborations between each other.

(Table 5). On further analysis, it was observed that seven organizations registered their publications output above their group average (23.87) and five organizations had CPP (44.36) and RCI (2.95) above the average.

\section{Most Productive Authors}

773 authors participated in the research on "Impact of Covid-19 and Sleep Disorders", of which top 15 authors published 6 to 9 papers each. Together they contributed to $6.28 \%$ (104) of the total publications share
Table 3: Subject-Wise Breakup of Publications on "Impact of Covid-19 and Sleep Disorders"

\begin{tabular}{clcccc}
\hline S.No & Subject & TP & TC & CPP & \%TP \\
\hline 1 & Medicine & 1390 & 20599 & 14.82 & 83.94 \\
2 & Neuroscience & 321 & 6646 & 20.70 & 19.38 \\
3 & Psychology & 169 & 3135 & 18.55 & 10.21 \\
4 & Biochemistry, Genetics \& Molecular & 120 & 1494 & 12.45 & 7.25 \\
& Biology & & & & \\
5 & Environment Science & 82 & 831 & 10.13 & 4.95 \\
6 & Pharmacology, Toxicology \& & 71 & 256 & 3.61 & 4.29 \\
& Pharmaceutics & & & & \\
7 & Immunology \& Microbiology & 53 & 2690 & 50.75 & 3.20 \\
& Global output & 1656 & 24928 & 15.05 & \\
\hline
\end{tabular}

TP=Total Papers; TC=Total Citations; $\mathrm{CPP}=$ Citations Per Paper

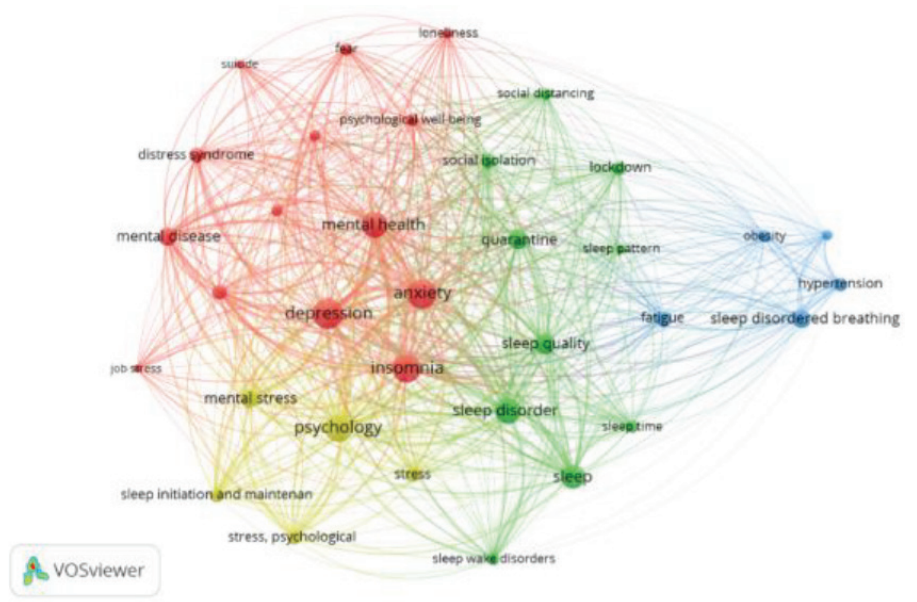

Figure 2: Mapping of Keyword Co-occurrence.

Figure 2 represents mapping of keywords which frequently emerged in the literature on "Impact of Covid-19 on Sleep Disorders" created using VOSviewer. The size of the dot represents number of occurrence of the keywords in the literature and the thickness of the linkage represents number of instances where both the linked keywords occurred together. Hence, the larger the number of publications in which both the keywords occur, the thickness is stronger and the distance between the terms is smaller in the visualization. These 34 keywords were classified in 4 clusters, the largest cluster is in red color, followed by cluster 2 in green color. The colors of the clusters are represented by the density of relation between the keywords.

and 56.2\% (14009) global citations share (Table 6). On further analysis, it was observed that nine of top 15 authors registered their publications output above the group average of 6.93: Z. Liu (9 papers), S. Grover, G. Wang and X. Zhang (8 papers each); Z. Cai, A. Mehra, C.M. Morin, S. Sahoo and B. Zhang (7 papers each). Further six of the top 15 authors registered their CPP (134.70) and RCI (8.95) above the group average of all authors and these authors were L. Kang (395.17 and 26.26), Y. Wang (395.17 and 26.26), S. Ma (322.0 and 21.4), G. Wang (278.75 and 18.52), Z. Cai (274.86 and 18.26) and Z. Liu (158.89 and 10.56) (Table 6).

\section{Medium of Research Communication}

Of the total papers, $99.58 \%$ (1649) appeared in journals, $0.24 \%$ appeared as conference proceedings and $0.18 \%$ as part of the book series. These papers appeared in 301 journals: 259 journals publishing 1-5 papers each, 23 journals published 6-10 papers each, 16 journals published 
11-50 papers each, 2 journals published 51-73 papers. The top 15 most productive journals accounted for $28.32 \%$ share of total publications in journals on the topic (Table 7).

\section{High-Cited Papers}

Of the total publications on "Impact of Covid-19 and Sleep Disorders", only $42(2.54 \%)$ papers accumulated 103 to 2177 CPP (cumulative total 14137 citations) since their publication during 2020-21, averaging 336.6 CPP.The distribution of these 42 highly cited papers was skewed: Eighteen papers were cited 103-198 times, 10 papers were cited 206-291 times, 8 papers were cited 304-456 times, 4 papers were cited 503-730 times and 2 papers were cited more than 1000 times (1470 and 2177 times).

Of the 42 high-cited papers, 30 were published as articles, 7 as reviews, 4 as letters and 1 as editorial.Of the 42 highly cited papers, 4 came from a single organization (non-collaborative papers) and 38 papers came from authors from two or more organizations (22 national collaborative and 16 international collaborative papers).

These 42 high-cited papers appeared in 28 journals, of which 6 papers were published in Brain, Behavior \& Immunity, 3 papers were published in Asian Journal of Psychiatry, 2 papers each in Frontiers in Psychiatry,

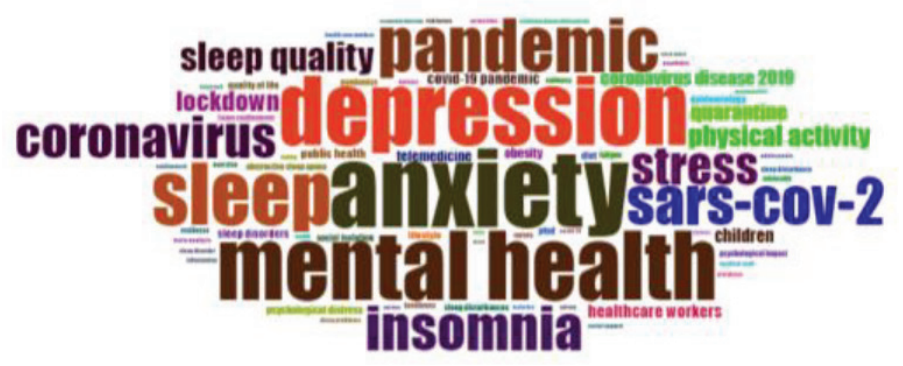

Figure 3: Word Cloud of the Keyword Co-occurrence.
Table 4: Significant Keywords Figuring in the Publications on "Impact of Covid-19 and Sleep Disorders"

\begin{tabular}{|c|c|c|c|c|c|}
\hline S.No & $\begin{array}{l}\text { Name of the } \\
\text { Keyword }\end{array}$ & Frequency & S.No & $\begin{array}{l}\text { Name of the } \\
\text { Keyword }\end{array}$ & Frequency \\
\hline 1 & Anxiety & 714 & 18 & $\begin{array}{l}\text { Sleep Initiation } \\
\text { and Maintence } \\
\text { Disorder }\end{array}$ & 147 \\
\hline 2 & Depression & 622 & 19 & Hypertension & 127 \\
\hline 3 & Insomnia & 562 & 20 & $\begin{array}{l}\text { Psychological } \\
\text { Stress }\end{array}$ & 123 \\
\hline 4 & Psychology & 502 & 21 & Fear & 121 \\
\hline 5 & Mental Health & 452 & 22 & Obesity & 116 \\
\hline 6 & Sleep Disorders & 432 & 23 & $\begin{array}{l}\text { Sleep Wake } \\
\text { Disorder }\end{array}$ & 116 \\
\hline 7 & Sleep & 383 & 24 & Sleep Time & 108 \\
\hline 8 & Quarantine & 282 & 25 & Lockdown & 107 \\
\hline 9 & Sleep Quality & 278 & 26 & $\begin{array}{l}\text { Psychological } \\
\text { Wellbeing }\end{array}$ & 105 \\
\hline 10 & $\begin{array}{l}\text { Sleep Disorder } \\
\text { Breathing }\end{array}$ & 228 & 27 & $\begin{array}{l}\text { Social } \\
\text { Distancing }\end{array}$ & 100 \\
\hline 11 & Mental Stress & 224 & 28 & Social Support & 95 \\
\hline 12 & Mental Disease & 213 & 29 & $\begin{array}{l}\text { Copying } \\
\text { Behavior }\end{array}$ & 92 \\
\hline 13 & Postraumatic Stress & 178 & 30 & $\begin{array}{l}\text { Diabetes } \\
\text { Mellitus }\end{array}$ & 84 \\
\hline 14 & Social Isolation & 172 & 31 & Loneliness & 77 \\
\hline 15 & Stress & 156 & 32 & Sleep Pattern & 71 \\
\hline 16 & Distress Syndrome & 151 & 33 & Job Stress & 55 \\
\hline 17 & Fatique & 150 & 34 & Suicide & 55 \\
\hline
\end{tabular}

Table 5: Top 15 Most Productive Organizations in "Impact of Covid-19 and Sleep Disorders"

\begin{tabular}{|c|c|c|c|c|c|c|c|c|}
\hline S.No & Name of the Organization & TP & TC & CPP & $\mathrm{HI}$ & ICP & \%ICP & $\mathrm{RCl}$ \\
\hline 1 & Huazhong University of Science and Technology, China & 40 & 2103 & 52.58 & 14 & 8 & 20.00 & 3.49 \\
\hline 2 & Tongji Medical College, China & 38 & 715 & 18.82 & 12 & 11 & 28.95 & 1.25 \\
\hline 3 & Harvard Medical School, USA & 33 & 623 & 18.88 & 8 & 6 & 18.18 & 1.25 \\
\hline 4 & Renmin Hospital of Wuhan University, China & 29 & 3135 & 108.10 & 13 & 9 & 31.03 & 7.18 \\
\hline 5 & Sapienza University of Rome, Italy & 28 & 778 & 27.79 & 11 & 12 & 42.86 & 1.85 \\
\hline 6 & INSERM, France & 24 & 577 & 24.04 & 8 & 6 & 25.00 & 1.60 \\
\hline 7 & University of Toronto, Canada & 24 & 628 & 26.17 & 9 & 14 & 58.33 & 1.74 \\
\hline 8 & Capital Medical University, China & 20 & 3077 & 153.85 & 7 & 8 & 40.00 & 10.22 \\
\hline 9 & All India Institute of Medical Sciences, New Delhi & 19 & 67 & 3.53 & 4 & 2 & 10.53 & 0.23 \\
\hline 10 & AP-HP Assistance Publique-Hopitaux de Paris, France & 18 & 336 & 18.67 & 8 & 3 & 16.67 & 1.24 \\
\hline 11 & Wuhan University, China & 18 & 1968 & 109.33 & 11 & 6 & 33.33 & 7.26 \\
\hline 12 & Southern Medical University, China & 17 & 967 & 56.88 & 6 & 8 & 47.06 & 3.78 \\
\hline 13 & University of Ottawa, Canada & 17 & 172 & 10.12 & 6 & 8 & 47.06 & 0.67 \\
\hline 14 & University of Milano, Italy & 17 & 699 & 41.12 & 8 & 6 & 35.29 & 2.73 \\
\hline \multirow[t]{4}{*}{15} & University of Sao Paulo, Brazil & 16 & 35 & 2.19 & 4 & 6 & 37.50 & 0.15 \\
\hline & Total of 15 organizations & 358 & 15880 & 44.36 & 8.6 & 113 & 31.56 & 2.95 \\
\hline & Global total & 1656 & 24928 & 15.05 & & & & \\
\hline & Share of top 15 organizations in global total & 21.62 & 63.70 & & & & & \\
\hline
\end{tabular}

TP=Total Papers; TC=Total Citations; CPP=Citations Per Paper; ICP=International Collaborative Papers; HI=H-Index; RCI=Relative Citation Index 
Table 6: The 15 Most Productive Authors on "Impact of Covid-19 on Sleep Disorders"

\begin{tabular}{|c|c|c|c|c|c|c|c|c|c|}
\hline S.No & Name of the Author & Affiliation of the Author & TP & TC & CPP & $\mathrm{HI}$ & ICP & \%ICP & $\mathrm{RCl}$ \\
\hline 1 & Z. Liu & Renmin Hospital of Wuhan University, China & 9 & 1430 & 158.89 & 6 & 3 & 33.33 & 10.56 \\
\hline 2 & S. Grover & $\begin{array}{l}\text { Postgraduate Institute of Medical Education \& } \\
\text { Research, Chandigarh, India }\end{array}$ & 8 & 79 & 9.88 & 5 & 0 & 0.00 & 0.66 \\
\hline 3 & G. Wang & Renmin Hospital of Wuhan University, China & 8 & 2230 & 278.75 & 4 & 1 & 12.50 & 18.52 \\
\hline 4 & X. Zhang & Institute of Psychology, CAS, China & 8 & 54 & 6.75 & 5 & 1 & 12.50 & 0.45 \\
\hline 5 & Z.Cai & Renmin Hospital of Wuhan University, China & 7 & 1924 & 274.86 & 4 & 2 & 28.57 & 18.26 \\
\hline 6 & A.Mehra & $\begin{array}{l}\text { Postgraduate Institute of Medical Education \& } \\
\text { Research, Chandigarh, India }\end{array}$ & 7 & 79 & 11.29 & 5 & 0 & 0.00 & 0.75 \\
\hline 7 & C.M. Morin & University of Laval, Canada & 7 & 37 & 5.29 & 3 & 3 & 42.86 & 0.35 \\
\hline 8 & S. Sahoo & $\begin{array}{l}\text { Postgraduate Institute of Medical Education \& } \\
\text { Research, Chandigarh, India }\end{array}$ & 7 & 79 & 11.29 & 5 & 0 & 0.00 & 0.75 \\
\hline 9 & B. Zhang & Southern Medical University, China & 7 & 657 & 93.86 & 2 & 2 & 28.57 & 6.24 \\
\hline 10 & T. Cheung & Hong Kong Polytechnic University & 6 & 331 & 55.17 & 3 & 6 & 100.00 & 3.67 \\
\hline 11 & L.Kang & Renmin Hospital of Wuhan University, China & 6 & 2371 & 395.17 & 4 & 2 & 33.33 & 26.26 \\
\hline 12 & S. Ma & Renmin Hospital of Wuhan University, China & 6 & 1932 & 322.00 & 4 & 3 & 50.00 & 21.40 \\
\hline 13 & R.S. McIntyre & University of Toronto, Canada & 6 & 392 & 65.33 & 6 & 2 & 33.33 & 4.34 \\
\hline 14 & Y. Wang & Renmin Hospital of Wuhan University, China & 6 & 2371 & 395.17 & 4 & 2 & 33.33 & 26.26 \\
\hline \multirow[t]{4}{*}{15} & Y. Zhou & Institute of Psychology, CAS, China & 6 & 43 & 7.17 & 4 & 0 & 0.00 & 0.48 \\
\hline & & Total of top 15 authors & 104 & 14009 & 134.70 & 4.27 & 27 & 25.96 & 8.95 \\
\hline & & Global total & 1656 & 24928 & 15.05 & & & & \\
\hline & & Share of top 15 authors in global total & 6.28 & 56.20 & & & & & \\
\hline
\end{tabular}

TP=Total Papers; TC=Total Citations; $\mathrm{CPP}=$ Citations Per Paper; ICP=International Collaborative Papers; HI=H-Index; RCI=Relative Citation Index

Table 7: Top 15 Most Productive Journals on “Impact of Covid-19 and Sleep Disorders"

\begin{tabular}{clccc}
\hline S.No & Name of the Journal & TP & TC & CPP \\
\hline 1 & International Journal of Environment & 73 & 805 & 11.03 \\
& Research \& Public health & & & \\
2 & Sleep Medicine & 69 & 439 & 6.36 \\
3 & Frontiers in Psychiatry & 49 & 483 & 9.86 \\
4 & Journal of Clinical Sleep Medicine & 47 & 181 & 3.85 \\
5 & Psychiatry Research & 40 & 1646 & 41.15 \\
6 & Asian Journal of Psychiatry & 32 & 1497 & 46.78 \\
7 & Journal of Affective Disorders & 28 & 342 & 12.21 \\
8 & Brain, Behavior \& Immunity & 24 & 2065 & 86.04 \\
9 & PLOS One & 21 & 113 & 5.38 \\
10 & Nutrients & 18 & 455 & 25.28 \\
11 & Frontiers in Psychology & 15 & 77 & 5.13 \\
12 & Journal of Medical Internet Research & 14 & 227 & 16.21 \\
13 & Journal of Sleep Research & 14 & 394 & 28.14 \\
14 & International Journal of Research in & 12 & 6 & 0.50 \\
& Pharmaceutical Sciences & & & \\
15 & BMJ Open & 11 & 12 & 1.09 \\
& Total of 15 journals & 467 & 8742 & 18.72 \\
& Global total & 1649 & & \\
\hline & Share of top 15 journals in gobal total & 28.32 & & \\
\hline
\end{tabular}

TP=Total Papers; $\mathrm{TC}=$ Total Citations; $\mathrm{CPP}=$ Citations Per Paper
JAMA Network Open, Journal of Sleep Research, Lancet Psychiatry, Medical Science Monitor, New England Journal of Medicine and Psychiatry Research.

\section{DISCUSSION}

The present paper examined the publications on "Impact of Covid-19 and Sleep Disorders". Our analysis shows that since the onset of the pandemic, 1656 papers emerged on this topic, which were cited 24928 times with an average CPP of 15.05. However, only one-fifth of these publications were supported by extramural funding. The publications based on external funding had higher CPP (34.59), compared to all the publications on the topic. When one attempts to understand the emrgence of literature on "Covid-19 and Sleep Disorders", it can be said that the Covid-19 pandemic has possibly led to more rapid proliferation of the literature on sleep disorders, compared to earlier times. ${ }^{7,8}$ During the Covid-19 pandemic, majority of the publications on the topic emerged from USA, followed by China, Italy, U.K. and India. Previous analysis of publications on insomnia also suggest that majority of the publications emerge from USA ${ }^{8}$ and the same trend has followed during the Covid-19 pandemic. Previous bibliometric study on insomnia, showed that maximum number of publications emerged by G-7 countries (Canada, France, Germany, Italy, Japan, the U.K. and the USA). ${ }^{8}$ When one compares the finding of the present study with this, it can be said that the studies on "Impact of Covid-19 on Sleep Disorders" were possibly influenced by the incidence of the Covid-19 in the countries. A higher number of publications from China can be understood in the background of the fact, that the pandemic emerged from the same country. The present analysis suggests that the share of international collaborative papers from the top 10 countries varied from $20.44 \%$ to $63.93 \%$, with average value as $37.97 \%$. Authors from USA had strong collaborative 
linkages with authors from China, U.K. Canada, and Italy. This finding is in the same direction of collaborative linkages for Covid-19 research per se. ${ }^{10}$

In terms of keywords, commonly occurring key words in "Impact of Covid-19 and Sleep Disorders" research included anxiety, depression, and mental health. The higher co-occurrence of these words in the sleep literature could be understood from the fact that most of the studies during the Covid-19 pandemic have evaluated depression, anxiety, stress and sleep disturbance together. Further sleep disturbance is also understood as a symptom of these disorders. Previous insomnia bibliometric analysis also showed similar trends. ${ }^{8}$ The top 15 organizations and authors contributed to $21.62 \%$ and $6.28 \%$ of the publications share respectively and $63.7 \%$ and $56.2 \%$ of the total citations share.

Previous analysis of the insomnia literature showed that Harvard University from the USA was the most productive institution. ${ }^{8}$ However, the present analysis showed that 4 out of the 5 universities in sleep research during the Covid-19 pandemic were from China, with Harvard Medical School emerging as the third most productive institution. This difference could be possibly due to the fact that the Covid-19 emerged in China and later spread to other countries with a lag period of few months. This possibly led to authors from China publishing more research on the topic.

In terms of most productive journals, the top 5 journals which published higher number of articles included International Journal of Environment Research and Public health, Sleep Medicine, Frontiers in Psychiatry, Journal of Clinical Sleep Medicine and Psychiatry Research. Previous bibliometric analysis of insomnia publications showed that Journal of Sleep and Sleep Medicine published maximum number of publications on the topic. ${ }^{8}$ The change in the profile of the journals publishing "Covid-19 and Sleep Disorders" research could have been influenced by the other topics being concomitantly researched along with the sleep disorders.

The present analysis has certain strength and limitations. The present analysis was based on the Scopus database, which has wider coverage of journals when compared to other databases like PubMed. The analysis included papers covered under more than one subject area. The analysis was done as per the publication records as on 14 May 2021 and the literature on the topic is rapidly emerging. The present analysis did not evaluate the exact type of publications, and quality of the papers.

\section{CONCLUSION}

To conclude, the present study shows that since the beginning of the pandemic, large number of publications have focused on "Impact of Covid-19 on Sleep Disorders". The majority of the publications have emerged from USA, China, Italy, U.K., India and Canada. The maximum number of publications have been published in the International Journal of Environment Research and Public Health, Sleep Medicine, followed by Frontiers in Psychiatry, and Journal of Clinical Sleep Medicine. In terms of CPP, Pediatrics, Brain, Behavior and Immunity, Asian Journal of Psychiatry, Psychiatry Research, Journal of Sleep Research and Nutrients were the leading journals.

\section{CONFLICT OF INTEREST}

The authors declare no conflict of interest.

\section{ABBREVIATIONS}

Covid-19: 2019 Novel Corona Virus disease.

\section{REFERENCES}

1. During EH, Kawai M. The functions of sleep and the effects of sleep deprivation. In: Mittchell G, editor Miglis. Sleep and neurologic disease. Academic Press; 2017. p. 55-72.

2. Van Reeth O, Weibel L, Spiegel K, Leproult R, Dugovic C, Maccari S. PHYSIOLOGY OF SLEEP (REVIEW)-Interactions between stress and sleep: from basic research to clinical situations. Sleep Med Rev. 2000;4(2):201-19. doi: 10.1053/ smrv.1999.0097.

3. Hossain MM, Tasnim S, Sultana A, Faizah F, Mazumder H, Zou L, McKyer ELJ, Ahmed HU, Ma P. Epidemiology of mental health problems in Covid-19: a review. F1000Res. 2020 June 23;9:636. doi: 10.12688/f1000research.24457.1, PMID 33093946.

4. Lin YN, Liu ZR, Li SQ, Li CX, Zhang L, Li N, Sun X. W, Li, H. P. Zhou, J. P. and, Q.Y. Burden of sleep disturbance during Covid-19 Pandemic: A systematic review. Nat Sci Sleep. June 28 2021;28(3):933-66.

5. Al Maqbali M, Al Sinani M, Al-Lenjawi B. Prevalence of stress, depression, anxiety and sleep disturbance among nurses during the Covid-19 pandemic: A systematic review and meta-analysis. J Psychosom Res. February 2021;141:110343. doi: 10.1016/j.jpsychores.2020.110343.

6. Deng Z, Chen J, Wang T. Bibliometric and visualization analysis of human coronaviruses: prospects and implications for Covid-19 research. Front Cell Infect Microbiol. 2020;10:581404. doi: 10.3389/fcimb.2020.581404.

7. Robert C, Wilson CS, Gaudy JF, Arreto C. The evolution of the sleep science literature over 30 years: A bibliometric analysis. Scientometrics. 2007;73(2):231-56. doi: 10.1007/s11192-007-1780-2.

8. Jallow AW, Wang M-H, Ho Y-S. Global research trends and publications of insomnia: A bibliometric analysis. COLLNET J Scientometr Inf Manag. 2020;14(2):349-67. doi: 10.1080/09737766.2021.1906184.

9. Park BS, Kim IH, Park KM. Top 100 cited articles on sleep medicine: A bibliometric analysis. Eur Neurol. 2020;83(1):111-20. doi: 10.1159/000507393, PMID 32344406.

10. Gupta BM, Dhawan S, Mueen Ahmed K, Mamdapur GM. Global research on Covid-19 disease: A scientific assessment of publications during 2020-21. IJMEDPH. 2021;11(2):76-84. doi: 10.5530/ijmedph.2021.2.14. 